\title{
Crystal structure of anilinium perchlorate, $\mathrm{C}_{6} \mathrm{H}_{5} \mathrm{NH}_{3}{ }^{+} \mathrm{ClO}_{4}{ }^{-}$
}

\author{
J. A. Paixão, A. Matos Beja, M. Ramos Silva, L. Alte da Veiga \\ Universidade de Coimbra, Faculdade de Ciências e Tecnologia, Departamento de Física, P-3000 Coimbra, Portugal
}

\author{
and J. Martin-Gil
}

ETSII, Departamento de Química Inorgànica, Paseo del Cauce, s/n, SP-47011 Valladolid, Spain

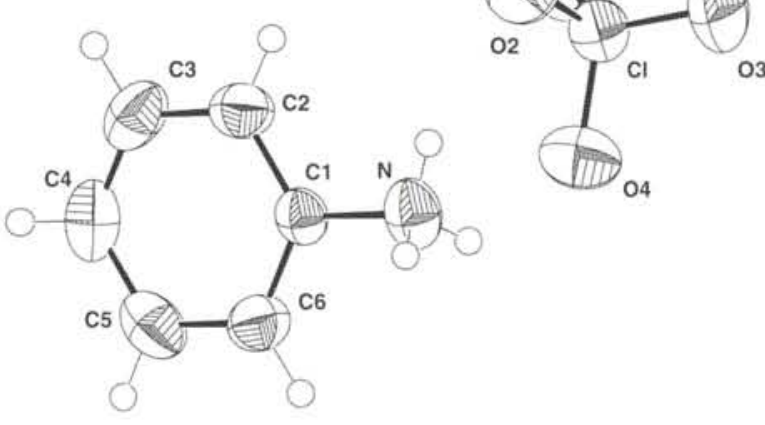

\footnotetext{
Abstract

$\mathrm{C}_{6} \mathrm{H}_{8} \mathrm{ClNO}_{4}$, orthorhombic, $P 2{ }_{12} 2_{1}$ (No. 19), $a=5.895$ (3) $\AA$, $b=7.505(5) \AA, c=18.909$ (7) $\AA, V=836.6 \AA^{3}, Z=4$,

$R_{\mathrm{gt}}(F)=0.039, R_{\mathrm{w}}\left(F^{2}\right)=0.092, T=293 \mathrm{~K}$.
}

\section{Source of material}

The title compound was prepared by reacting an aqueous solution of $N, N^{\prime}$-diphenylformamidine $\left(98^{\circ}\right.$, Aldrich) with perchloric acid and the precipitate was solubilized in ethanol. [Caution: perchlorates are potential explosives!]. Violet, large single crystals of prismatic form grew from the solution, by slow evaporation, over a period of a few days from which one small piece was cut and used for the X-ray analysis.

The H-atoms of the phenyl ring were placed at calculated positions and refined as riding using the SHELXL-97 defaults: C(aryl)$\mathrm{H}=0.93 \AA, U(\mathrm{H})_{\mathrm{eq}}=1.2 U_{\mathrm{eq}}$ of the parent $\mathrm{C}$ atom [1]. A difference Fourier map revealed that the $\mathrm{NH}_{3}{ }^{+}$group exhibits rotational disorder. Instead of well defined peaks for the hydrogen atoms, a ring of uniform residual density was observed. Although it is possible that the $\mathrm{NH}_{3}{ }^{+}$group is rotating rather freely at room temperature, we tried to model this residual density assuming that the disorder corresponds to two alternate positions. The conformation of one of the disordered $\mathrm{NH}_{3}{ }^{+}$groups was choosen such that one $\mathrm{H}$ atom is eclipsed with the ring (the most commonly found conformation in anilinium salts) and the other $\mathrm{NH}_{3}{ }^{+}$group is rotated from this position by $60^{\circ}$ around the $\mathrm{C}-\mathrm{N}$ bond, so that the positions of the $\mathrm{H}$ atoms define a regular hexagon. A single isotropic displacement parameter $U(\mathrm{H})=1.5 U_{\mathrm{eq}}(\mathrm{N})$ was assigned to the six $\mathrm{H}$ atoms. The occupation of these two groups was refined with one free variable such that the two occupations were constrained to add up to unity. The refined values are $0.54(4)$ 0.46(4).

\begin{abstract}
Discussion
The $\mathrm{N}-\mathrm{H}$ distance was allowed to change during refinement and was converged to $0.83 \AA$. The intramolecular bond distances and angles of the anilinium cation are in good agreement with literature data $[2-5]$. The ring is planar within $0.002 \AA$ but the $\mathrm{N}$ atom deviates by $-0.025(6) \AA$ from the least squares plane. There are small differences in the aromatic $\mathrm{C}-\mathrm{C}$ bond length and endocyclic bond angles of the phenyl ring expected from the $\sigma$-electron widthdrawing character of the $\mathrm{NH}_{3}{ }^{+}$group. The $\mathrm{Cl}-\mathrm{N}$ distance $[1.466(3) \AA]$ and the $\mathrm{C} 6-\mathrm{C} 1-\mathrm{C} 2$ angle ipso to the $\mathrm{N}$ atom $\left[121.9(3)^{\circ}\right]$ are in good agreement with the average values [1.462(2) $\AA$ and $\left.121.7(2)^{\circ}\right][6]$ for the anilinium cation. The geometry of the anion is unexceptional. The average $\mathrm{Cl}-\mathrm{O}$ $[1.413(8) \AA]$ distance and $\mathrm{O}-\mathrm{Cl}-\mathrm{O}$ angle $\left[109.5(7)^{\circ}\right]$ are comparable to those observed in otherperchlorate salts [7]. There are no solvent-accessible voids in the crystal lattice.
\end{abstract}

Table 1. Data collection and handling.

$\begin{array}{ll}\text { Crystal: } & \text { light violet, prismatic, } \\ & \text { size } 0.15 \times 0.24 \times 0.37 \mathrm{~mm} \\ \text { Wavelength: } & \text { Mo } K_{\alpha} \text { radiation }(0.71073 \AA) \\ \mu: & 4.31 \mathrm{~cm}^{-1} \\ \text { Diffractometer, sacn mode: } & \text { Enraf-Nonius CAD4, } \omega / 2 \theta \\ 2 \theta_{\text {max }}: & 55.16^{\circ} \\ N(h k l)_{\text {measured }}, N(h k l)_{\text {unique: }} & 2210,1931 \\ \text { Criterion for } I_{\text {obs }}, N(h k l)_{\text {gi }}: & I_{\text {obs }}>2 \sigma\left(I_{\text {obs }}\right), 1334 \\ N(\text { param })_{\text {refined: }} & 111 \\ \text { Programs: } & \text { SHELXL-97 [1], XCAD4[9], SDP [10], } \\ & \text { ORTEPII [12], SHELXS-97 [12] }\end{array}$

Table 2. Atomic coordinates and displacement parameters (in $\AA^{2}$ ).

\begin{tabular}{lllllll}
\hline Atom & Site & Occ. & $x$ & $y$ & $z$ & $U_{\text {iso }}$ \\
\hline $\mathrm{H}(\mathrm{IA})$ & $4 a$ & $0.54(4)$ & $0.866(3)$ & $0.598(1)$ & $0.5633(4)$ & 0.079 \\
$\mathrm{H}(\mathrm{IB})$ & $4 a$ & 0.54 & $0.634(3)$ & $0.604(1)$ & $0.5636(4)$ & 0.079 \\
$\mathrm{H}(\mathrm{IC})$ & $4 a$ & 0.54 & $0.7434(9)$ & $0.443(3)$ & $0.5668(3)$ & 0.079 \\
$\mathrm{H}(\mathrm{ID})$ & $4 a$ & $0.46(4) 0.629(3)$ & $0.499(1)$ & $0.5658(4)$ & 0.079 \\
$\mathrm{H}(\mathrm{IE})$ & $4 a$ & 0.46 & $0.862(3)$ & $0.493(1)$ & $0.5655(4)$ & 0.079 \\
$\mathrm{H}(\mathrm{F})$ & $4 a$ & 0.46 & $0.7517(9)$ & $0.654(3)$ & $0.5623(5)$ & 0.079 \\
$\mathrm{H}(2)$ & $4 a$ & & 1.0513 & 0.6872 & 0.6640 & 0.061 \\
$\mathrm{H}(3)$ & $4 a$ & & 1.0531 & 0.6973 & 0.7868 & 0.072 \\
$\mathrm{H}(4)$ & $4 a$ & & 0.7606 & 0.5808 & 0.8502 & 0.072 \\
$\mathrm{H}(5)$ & $4 a$ & & 0.4564 & 0.4520 & 0.7930 & 0.071 \\
$\mathrm{H}(6)$ & $4 a$ & & 0.4500 & 0.4386 & 0.6705 & 0.061 \\
\hline
\end{tabular}


Table 3. Atomic coordinates and displacement parameters (in $\AA^{2}$ ).

\begin{tabular}{|c|c|c|c|c|c|c|c|c|c|c|}
\hline Atom & Site & $x$ & $y$ & $z$ & $U_{11}$ & $U_{22}$ & $U_{33}$ & $U_{12}$ & $U_{13}$ & $U_{23}$ \\
\hline $\mathrm{Cl}$ & $4 a$ & $0.2574(2)$ & $0.52553(8)$ & $0.96647(4)$ & $0.0597(4)$ & $0.0375(3)$ & $0.0440(3)$ & $-0.0020(7)$ & $0.0001(7)$ & $0.0055(3)$ \\
\hline$O(1)$ & $4 a$ & $0.258(1)$ & $0.6728(3)$ & $0.9208(2)$ & $0.119(2)$ & $0.050(1)$ & $0.098(2)$ & $-0.001(3)$ & $0.009(4)$ & $0.030(1)$ \\
\hline$O(2)$ & $4 a$ & $0.0558(6)$ & $0.4257(5)$ & $0.9539(2)$ & $0.068(2)$ & $0.077(3)$ & $0.093(3)$ & $-0.022(2)$ & $0.002(2)$ & $-0.005(2)$ \\
\hline$O(3)$ & $4 a$ & $0.2676(9)$ & $0.5772(5)$ & $1.0383(1)$ & $0.107(2)$ & $0.131(3)$ & $0.050(1)$ & $0.009(3)$ & $-0.004(3)$ & $-0.025(2)$ \\
\hline$O(4)$ & $4 a$ & $0.4500(6)$ & $0.4133(5)$ & $0.9505(2)$ & $0.071(2)$ & $0.058(2)$ & $0.091(3)$ & $0.015(2)$ & $0.007(2)$ & $0.000(2)$ \\
\hline $\mathrm{N}$ & $4 a$ & $0.7478(9)$ & $0.5505(3)$ & $0.5793(1)$ & $0.073(2)$ & $0.041(1)$ & $0.044(1)$ & $0.005(3)$ & $-0.002(3)$ & $-0.0004(9)$ \\
\hline$C(1)$ & $4 a$ & $0.7492(9)$ & $0.5610(3)$ & $0.6568(1)$ & $0.047(2)$ & $0.030(1)$ & $0.039(1)$ & $0.002(2)$ & $-0.001(3)$ & $0.0002(9)$ \\
\hline $\mathrm{C}(2)$ & $4 a$ & $0.9318(7)$ & $0.6395(5)$ & $0.6899(2)$ & $0.047(2)$ & $0.046(2)$ & $0.059(2)$ & $-0.006(2)$ & $-0.000(2)$ & $0.002(2)$ \\
\hline $\mathrm{C}(3)$ & $4 a$ & $0.9316(8)$ & $0.6452(5)$ & $0.7632(2)$ & $0.064(2)$ & $0.055(2)$ & $0.062(2)$ & $0.001(2)$ & $-0.021(2)$ & $-0.011(2)$ \\
\hline$C(4)$ & $4 a$ & $0.758(1)$ & $0.5761(4)$ & $0.8010(2)$ & $0.078(2)$ & $0.058(2)$ & $0.044(2)$ & $0.018(3)$ & $-0.008(3)$ & $0.000(1)$ \\
\hline $\mathrm{C}(5)$ & $4 a$ & $0.5761(7)$ & $0.4988(5)$ & $0.7669(2)$ & $0.060(2)$ & $0.058(2)$ & $0.059(2)$ & $0.003(2)$ & $0.016(2)$ & $0.012(2)$ \\
\hline$C(6)$ & $4 a$ & $0.5717(6)$ & $0.4909(5)$ & $0.6939(2)$ & $0.047(2)$ & $0.048(2)$ & $0.057(2)$ & $-0.006(2)$ & $-0.006(2)$ & $0.001(2)$ \\
\hline
\end{tabular}

Acknowledgments. The authors are indebted to Dr. J. C. Prata Pina for his invaluable assistance in the maintenance of the CAD-4 diffractometer. This work was supported by FCT.

\section{References}

1. Sheldrick, G. M.: SHELXL-97, a program for refining crystal structures University of Göttingen, Germany 1997.

2. Larsen, K. P.: The crystal structure of anilinium tetrachlorocuprate(II). Acta Chem. Scand. A28 (1974) 194-200.

3. Needham, G.; Johnson, P. L.; Williams, J. M.: Structural studies of precursor and partially oxidized conducting complexes. V. A neutron diffraction study of dianilinium tetracyanoplatinate. Acta Crystalogr. B33 (1977) 1581-1583.

4. Idrissi, A. K.; Rafiq, M.; Gougeon, P.; Guerin, R.: Anilinium hydrogen monofluorophosphate, $\mathrm{C}_{6} \mathrm{H}_{8} \mathrm{~N}^{+} \cdot \mathrm{HPO}_{3}^{-}$. Acta Crystallogr. $\mathrm{C51}$ (1995) 1359-1361.
5. Román, P; Beitia, J. I.; Luque, A.; Guzmán-Miralles, C.: Synthesis, chemical characterization and crystal structure of the anilinium bis $(1,2$ dithiooxalato-S, $S^{\prime}$ )nickelate(II). Polyhedron 15 (1996) 1071-1077.

6. Domenicano, A.; Serantoni, E. F.; Sanseverino, L. R.: Structural studies of benzene derivatives. I. Refinement of the crystal structure of $p$-phenylenediamine dihydrochloride. Acta Crystalogr. B33 (1977) 1664-1668.

7. Paixão, J. A.; Pereira Silva, P. S.; Matos Beja, A.; Ramos Silva, M.; Alte da Veiga, L.: Crystal Structure of $N, N^{\prime}$-diphenylguanidinium perchlorate $\left(\mathrm{C}_{13} \mathrm{H}_{14} \mathrm{~N}_{3}\right)\left(\mathrm{ClO}_{4}\right)$. Z. Kristallogr. NCS 213 (1998) 419-420.

8. Spek, A. L.: PLATON. Molecular Geometry Program. University of Utrecht, Utrecht, The Netherlands 1995.

9. Enraf Nonius. CAD4 Software, Version 5.0. Enraf Nonius, Delft, The Netherlands 1989.

10. Frenz, B. A.: Enraf Nonius SDP-plus Structure Determination Package. Version 3.0. Enraf-Nonius, Delft, The Netherlands 1985.

11. Johnson, C. K.: ORTEPII. Report ORNL-5138. Oak Ridge National Laboratory, Tennessee, USA 1976.

12. Sheldrick, G. M.: Phase annealing in SHELX-90: direct methods for larger structures. Acta Crystalogr. A46 (1990) 467-473. 